\title{
Article \\ Dialogicity in Individual and Institutional Scientific Blogs
}

\author{
Marina Bondi
}

Citation: Bondi, M. Dialogicity in Individual and Institutional Scientific Blogs. Publications 2022, 10, 9. https://doi.org/10.3390/ publications10010009

Academic Editors: Pilar Mur-Dueñas and Rosa Lorés

Received: 18 November 2021

Accepted: 27 January 2022

Published: 21 February 2022

Publisher's Note: MDPI stays neutral with regard to jurisdictional claims in published maps and institutional affiliations.

Copyright: (C) 2022 by the author. Licensee MDPI, Basel, Switzerland. This article is an open access article distributed under the terms and conditions of the Creative Commons Attribution (CC BY) license (https:/ / creativecommons.org/licenses/by/ $4.0 /)$.

\begin{abstract}
Dipartimento di Studi Linguistici e Culturali, University of Modena and Reggio Emilia 1, 40124 Modena, Italy; marina.bondi@unimore.it
\end{abstract}

\begin{abstract}
The paper focuses on variation across institutional and individual scientific blogs, i.e., blogs that are managed by journals, magazines or associations involved in the dissemination of scientific information and blogs that are managed by individual researchers. Using comparable corpora of posts from different scientific disciplines, look in particular at markers of dialogicity, i.e., the representation of participants (markers of self-reference, reader-reference, as well as representation of the scientific community and markers of attribution), markers of communicative action (organizational units and metastatements), and evaluative dialogue (evaluative lexis and dialogic contraction or expansion). Concordance analysis of keywords and key-phrases (as calculated by Wordsmith Tools 8.0) shows that blogs managed by individual scientists emphasize personal voice and interpersonal elements, while institutional blogs are comparatively more informational. Dialogicity markers are shown to contribute to defining how bloggers manage subjective and intersubjective positioning and construct their credibility, thus defining the nature of their relation to the audience and ultimately the functions of blogging.
\end{abstract}

Keywords: blog posts; dialogicity; identity; personal vs. institutional blogs

\section{Introduction}

Blogs have long attracted the attention of academic institutions for their promotional and outreach potential in the extended participatory framework of the Web [1]. As they are regularly updated web spaces with posts linked to relevant material and open to readers' comments (e.g., [2] (pp. 2-7)), blogs can be seen as "a designed space with many potential uses" [3] (p. 29) and virtual arenas where information is produced, shared and commented on evaluatively. They are characterized by a rather loose set of communicative purposes-typically dissemination of information, presenting personal attitudes, and networking [4,5]. Their peculiar combination of self-expression and knowledge sharing [6] has made them ideal places for identity and relationship management $[4,7]$. They have variable structures [8,9], but they are recognizedly "highly social" [10] (p. 435) and they are seen as places for "you to have your say" [11] (p. 99), often dominated by personal experiences and opinions rather than facts [12-14].

In a world qualified by a wide range of social media environments, blogs are certainly not the only-or even the main-digital tool available for scholars. Real-time collaborative writing tools and social media have been shown to influence scholarly writing deeply, e.g., [15,16]. Vlogs, podcasts and networking sites have greatly increased the possibilities of scholarly communication, thus often leading to awareness of a complex digital media ecology in scientific communication [17], where traditional and new media co-exist and build on each other. There has also been intense debate on the diminished status of blogs in many fields, especially in online debates [18,19], pointing at the need for blogs to reposition themselves in the context of a wide range of platforms. In political communication, for example, politicians have shown a clear preference for keeping in touch with the wider public through other social media (e.g., Twitter), but blogging remains a key tool of "citizen journalism" [20]. In the world of research and academia, blogs continue to be popular, even if often ephemerally so. There has in fact been a steady increase of research 
publications in blogs [21]. There may be different reasons for this. For one thing, blogs offer greater opportunity to engage with more complex forms of textuality and intertextuality than other social media; they also offer opportunities for "slow thinking" (less structured than traditional publications but more open to the development of an argument) [22], and they are more open to an undefined community, thus contributing to personal and institutional identity management [23].

Scholars use blogs to construct their identity as members of a disciplinary group, to highlight their authority and expertise and to enhance their visibility [13] (p. 162), [24]. The effectiveness of the materials posted may influence the scholar's reputation, and this in turn may emphasize the credibility of the information provided [25]. Blogs can then be seen as key resources providing evidence of the authority and expertise of scholars, constructing their visibility and identity as members of a discipline [13] (p. 162), with "personal knowledge" [12] (pp. 518-519) increasing the blogger's visibility, reputation and trust. Research blogs have attracted particular attention for their potential in developing as well as disseminating research [12,26-28]. They offer an opportunity to combine research and popularization [29], to present and discuss work in progress, to receive feedback from peers and at the same time interact with the general public [10] (p. 432), as "unknown, heterogeneous, and varied audiences may participate in co-constructing research debates" [30] (pp. 30-31). The format lends itself well to the processes of making scientific information accessible to general audiences: information is re-contextualized by means of "mediation, re-expression or translation of scientific issues into contexts that mean something to audiences" [31] (p. 88). It should be noted, however, that when interviewed regarding reasons for blogging, scholars have long shown [32] that they see blogging as a form of "common room" where they can discuss academic work conditions and policy contexts, share information and provide advice, as well as a form of "open access" resource, where they can get to print early and share ideas. This means that most academics blog for their peers rather than for the general public.

The format of blogs clearly offers great opportunities for the study of interactivity and writer/reader interaction [33]. Attention has been paid, on the one hand, to how interactive affordances open debate to patterns of agreement and disagreement [34] and even open conflict [14], and on the other to increased possibilities for collaborative research, interaction and feedback [30]. Discussions on blogs can add to bodies of knowledge and can contribute to building a reputation, but the "community of blogging practice" [4] is bound to include both experts and lay spectators or commenters, and it is difficult to say whether the intended audience of academic blogging is the collective witness of experimental science or the intended/universal audience of argumentative discourse [30]. The difference between scholarly communication and public communication is less marked (if not collapsed) on the web [35], as there is no actual control on the audience. Blogs can be seen as hybrid genres situated between academic and journalistic writing [36]. The possibility to engage in conversation and foster a sense of community is counterbalanced by the difficulty of predicting ideal readers and of establishing room for negotiations and predictions [37], in conditions of intentional or unintentional context collapse [38].

Academic bloggers engage with their readers in different ways; as shown by Zou and Hyland [39], for example, blogs in the social sciences tend to use more reader mentions, directives and questions, while life sciences and physical sciences blogs rely more on the authority of the writer and on shared understanding. Interactivity in the form of participant mentions is also shown to be very high in the comments when compared to the posts [40]. On the other hand, even if blogs somehow blur the distinction between science and public science, between internal communication and external communication, interaction among commenters often only takes the form of "interwoven polylogues" [41,42], i.e., multiparty conversations bringing together different audiences, which often alternate but do not always mingle. Participants with different backgrounds are thus allowed different ranges of verbal action and the interests of different types of participants seem to be dealt with on separate planes [43]; interwoven polylogues engage participants in parallel 
conversations, some of which are more clearly oriented to just sharing views, while others aim at knowledge dissemination and knowledge construction proper [44].

Authorship is also extremely variable in research blogs, as they are produced in a variety of different contexts by a wide range of authors, from researchers to professional science journalists, and their role is not always clearly identifiable. The present paper aims to focus on scholarly bloggers and to explore variation in authorial identity across institutional and individual scientific blogs, i.e., collective, multi-authored blogs that are managed by journals, magazines or associations involved in the dissemination of scientific information and blogs that are managed by individual researchers.

Using comparable corpora of blog posts from different areas in science, I look in particular at markers of dialogicity, i.e., markers of dialogic interaction between the writer and the reader. I look at this from three points of view [45]: the representation of participants, of communicative action and of the evaluative dialogue between writer and reader. The representation of participants can be analysed by looking at markers of self-reference or reader-reference such as first- and second-person pronouns, as well as through references to the discourse of the scientific community. The representation of communicative action can be studied by looking at units and patterns that are meant to structure discourse, such as connectors and discourse markers. The evaluative dimension of writer-reader dialogue can be seen through the evaluative lexis typically used in praise and criticism and the way this opens or restricts the space for negotiation of meaning on the part of the reader.

The expectation, actually confirmed by the data, is that blogs managed by individual scientists emphasize personal voice and interpersonal elements, while multi-authored institutional blogs are comparatively more informational. The questions that guide the analysis are questions regarding the nature of authorial "voice" in the two contexts, where individual blogs may be thought to be more focused on a single personality and reflect more their individual identity, while institutional blogs have posts written by many different authors and may therefore be taken to involve the individual identity of the blogger together with the collective identity of the organization itself. Are there differences in the way scholars manifest interaction with their readers in the two contexts? Are these differences mostly related to well-established forms of self-mention? Or do other features play a role too? And if so, what role?

The next section introduces the two corpora of blog posts used and the types of analysis adopted. Section 3 presents the results of the comparison and then looks at the language resources that characterize the posts of the two main types of blogs in light of the dialogic principle, looking at the single communicative action of the posts as dialogic and dependent on the communicative context. The conclusions summarize the discussion and look at the implications of the study.

\section{Materials and Methods}

The study is based on the Science Blogs Corpus compiled by Freddi (see [40] for a full presentation of the corpus). The corpus comprises posts and comments from a wide range of scientific disciplines (physics and astronomy, medicine and health, biology and life sciences, earth and environmental sciences) and is divided into two main sub-corpora:

- Individual blogs managed by "individual scientists who, despite having an institutional and academic affiliation, maintain a personal webpage where they blog freely about scientific issues of their own interest", including researchers of different seniority and institutional affiliations, all based in the US;

- Multi-authored institutional blogs that are "representative either of science magazines and newspapers [...] or of educational institutions, research centres and scientific journals running their own blogging networks" [40] (pp. 12-13).

Four blogs were chosen for each category. Selection criteria were based on top-ranking position, disciplinary area and degree of interactivity [40]. The distinction between the two sub-corpora is obviously more heuristic than ontological, as there is understandably a whole cline of possibilities in terms of authorial individuality of the blog. Some contextual 
information on the two sets of blogs may help understand the balance of individual and collective identities constituting the voice of each blogger.

The four individual blogs are managed by four academics characterized by different interests, different degrees of seniority and different forms of autonomy: two are fully independent individual blogs, whereas the other two are part of a network of blogs. "Skulls in the Stars" is managed by a blogger who signs with a pseudonym (Dr. Skyskull), but is also identified as associate professor of physics, specializing in optical science, at UNC Charlotte (US). "NeuroLogica Blog" is clearly attributed to Dr. Steven Novella, clinical neurologist, assistant professor at Yale University School of Medicine, also active as producer of a popular weekly science podcast, The Skeptics' Guide to the Universe, as well as in many other public organizations. On the other hand, "Genomics, Medicine and Pseudoscience", while authored exclusively by Steven Salzberg, Bloomberg Distinguished Professor at Johns Hopkins School of Medicine, is part of an independent network of science blogs called "Field of Science"; as explicitly stated by the website "although part of a network, bloggers on Field of Science exercise complete editorial freedom and own their blogs and content"1. Similarly, "Mountain Beltway"-authored by Callan Bentley, Assistant Professor of Geology at Piedmont Virginia Community College in Charlottesville, Virginia-is also part of a community of earth and space science blogs, hosted by the American Geophysical Union.

The four blogs that are classified as institutional are multi-authored scholarly blogs representing different types of organizations and different editorial policies. On the one hand we have the official blogs of PLOS (Public Library of Science) and Physics Buzz, the official blog of the American Physics Society. These are academic blogs hosting a number of diverse bloggers active in the world of research; both have their specific editorial policies-in favour of open science and open data for PLOS, advancing and diffusing the knowledge of physics for the benefit of humanity for APS. On the other hand, there are two blogs associated with two traditional popular science magazines: "Discover Magazine" and "Science News". These blogs are typically subdivided into sections covering different areas of science and host a high number of different bloggers, coming from the world of scientific research but often also pursuing a career in scientific journalism.

The present analysis is based on comparing the posts only, for a total of approximately 791 posts and 650,000 words. The collection covers a five-year span of the eight blogs, including approximately two posts per month between March 2014 and March 2019. The data are presented in Table 1.

Table 1. Composition of the blog post subcorpora.

\begin{tabular}{cccccc}
\hline \multicolumn{2}{c}{ Individual Blogs } & \multicolumn{3}{c}{ Institutional Blogs } \\
\hline Title & Word Count & No. Posts & Title & Word Count & No. Posts \\
\hline $\begin{array}{c}\text { Genomics, } \\
\text { Medicine and } \\
\begin{array}{c}\text { Pseudoscience } \\
\text { Mountain } \\
\text { Beltway }\end{array}\end{array}$ & 93,068 & 122 & $\begin{array}{c}\text { Discover } \\
\text { Magazine Blog }\end{array}$ & 83,714 & 120 \\
$\begin{array}{c}\text { Neuro Logica } \\
\text { Blog } \\
\text { Skulls in the } \\
\quad \text { Stars } \\
\text { Subtotal }\end{array}$ & 86,819 & 199 & Physics Buzz & 94,858 & 91 \\
\hline
\end{tabular}

The table shows that disciplinary representativeness is admittedly limited and not equally balanced across corpora and blogs, as the choice of posts was also determined by temporal sequence and appropriate availability of comments (for purposes that fall outside the scope of this study). This suggests focusing the analysis only on elements that might not be strictly related to disciplinary content, as comparison might otherwise be skewed. 
The post components of the corpus were first analysed using Wordsmith Tools 8.0 [42]. The quantitative study started with an overview of keywords and key-phrases, looking in particular at 4-word clusters, i.e., strings of contiguous word forms. The software defines keywords as word forms with frequencies that are higher or lower than an expected standard in statistically significant ways. Significant differences between the two corpora were explored by contrasting the two sets of posts. Contrasting the wordlists of personal and institutional blogs highlights the distinctive features of each corpus, i.e., those that vary in statistically significant ways. Examples are identified by abbreviation of the blog title and date of the post.

Attention was paid to both positive keywords (those that are significantly more frequent in the first corpus) and negative keywords (those that are significantly less frequent and therefore more frequent in the reference corpus). Frequency lists of 4-word clusters were also explored, on the assumption that phraseology is often a good indicator of typical uses and in order to be able to compare the results with those of Freddi [40], whose study focuses on the difference between posts and comments by studying keywords and 4-g, i.e., 4-word clusters.

Concordances were then studied to identify the effective role played by the word forms in context and the discourse function of the units they belonged to. This also meant paying attention to syntactic patterns and to collocation, colligation and "semantic preference", i.e., the tendency of a word form to co-occur with specific word forms, specific functional units and sets of lexical elements characterized by specific semantic traits [45].

The quantitative analysis focused on aspects that could be related to the dialogicity of posts. Following guidelines already applied to blogs [44], I looked at three dialogic perspectives: participant-oriented features, action-oriented features and evaluative dialogue.

From a participant-oriented perspective, the relevant dialogic features are those that identify the blogger and the community of writers/posters/readers evoked. This means paying particular attention not only to forms of self-reference and references to the reader (such as first- and second-person pronouns) (see for example [46] on self-mention and reader engagement as elements of metadiscourse), but also to the representation of the scholarly community and forms of attribution.

From an action-oriented perspective, the relevant features will be both those that contribute to interaction-oriented and text-oriented organizational units [47]: expressions that are used to manage writer-reader interaction (e.g., "as shown above") and words or phrases that manifest textual coherence, such as connectors and metatextual statements.

Finally, the perspective interested in evaluative dialogue (partly overlapping with the other two) will focus on how claims, arguments and attributions are assessed in both epistemic and attitudinal terms $[48,49]$, and how they position the reader in terms of acknowledging the need to negotiate topics and positions (dialogic expansion) or restricting the scope for negotiation (dialogic contraction) [50] (p. 102). See Figure 1 for an overview.

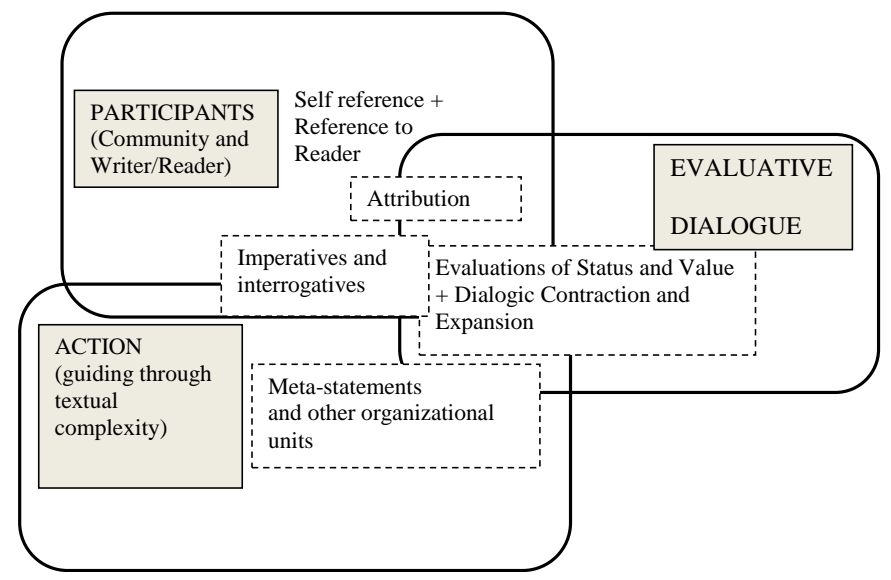

Figure 1. Elements of dialogicity [44] (p. 146). 
The results of the analysis are presented by dividing the keywords-identified by the software on a purely statistical basis-according to these three dialogic perspectives. It should be noted that keywords or key-phrases can often have more than one function and therefore cut across perspectives. A word form like "see", for example, could be used both to represent debate in a participant-oriented perspective ("they see this as") and to guide the reader ("See figure") in an action-oriented perspective. The various forms are presented under the heading that proved to be dominant in a preliminary concordance analysis.

\section{Results and Discussion}

\subsection{Participant-Oriented Dialogicity}

A study of positive and negative keywords and key-clusters provides a view of similarities and differences between the two sets of posts. Tables 2 and 3 below report selected keywords that were found to play a major role in participant-related dialogicity, such as pronouns referring to the writer and the reader or expressions referring to the discourse community. The discourse community is often referred to by identifying specific scientists, but also by plural and collective nouns referring to the community in general or to specific texts (in their paper or digital versions), as blog posts often take their origin from a text published in a scientific journal, a scientific report, another blog or a website devoted to relevant issues. The table ignores the specific names of authors cited, personal pronouns used to refer to them and references to specific disciplines (which may simply depend on an imbalance of disciplines in the two corpora); it includes, however, other general nominal elements that are used in the corpus to refer to the community and to relevant textual formats. These are listed using BIC (Bayesian information criterion) as the ordering principle, with positive keywords in descending order and negative keywords in ascending order. Frequencies are normalized per ten thousand words (pttw). Figures are rounded down (except for BIC data, where decimals may determine the order).

Table 2. Participant-related keywords: individual vs. institutional blog posts.

\begin{tabular}{|c|c|c|c|c|c|c|}
\hline Keyword & $\begin{array}{l}\text { Individual } \\
\text { Posts } \\
\text { Frequency }\end{array}$ & Pttw & $\begin{array}{c}\text { No. } \\
\text { Texts } \\
\text { (Individual Posts) }\end{array}$ & $\begin{array}{c}\text { Institutional } \\
\text { Posts } \\
\text { Frequency }\end{array}$ & Pttw & BIC \\
\hline$I$ & 2663 & 84 & 374 & 1073 & 31 & 838.52 \\
\hline Book & 307 & 9 & 88 & 34 & 1 & 264.45 \\
\hline Here & 557 & 17 & 239 & 174 & 0 & 235.24 \\
\hline$M y$ & 631 & 19 & 234 & 275 & 8 & 165.78 \\
\hline Title & 142 & 4 & 25 & 6 & 0 & 154.64 \\
\hline$M e$ & 366 & 11 & 183 & 115 & 3 & 148.92 \\
\hline Books & 76 & 2 & 44 & 12 & 0 & 44.67 \\
\hline$F D A$ & 97 & 3 & 23 & 23 & 0 & 42.88 \\
\hline Post & 173 & 5 & 92 & 71 & 2 & 40.68 \\
\hline Doctor & 72 & 2 & 35 & 13 & 0 & 37.42 \\
\hline$A m / ' m$ & 120 & 4 & 80 & 45 & 1 & 29.17 \\
\hline Article & 121 & 4 & 62 & 46 & 1 & 28.91 \\
\hline College & 94 & 3 & 48 & 30 & 1 & 27.54 \\
\hline Let's & 53 & 2 & 40 & 9 & 0 & 25.43 \\
\hline $\mathrm{NIH}$ & 91 & 3 & 23 & 32 & 1 & 21.89 \\
\hline Blog & 87 & 3 & 54 & 30 & 1 & 21.18 \\
\hline Website & 52 & 2 & 34 & 11 & 0 & 19.55 \\
\hline Readers & 39 & 1 & 34 & 10 & 0 & 7.75 \\
\hline Writing & 69 & 2 & 52 & 29 & 1 & 7.36 \\
\hline Posts & 43 & 1 & 26 & 13 & 0 & 6.46 \\
\hline Doctors & 54 & 2 & 25 & 22 & 1 & 3.65 \\
\hline Fiction & 51 & 2 & 22 & 21 & 1 & 2.44 \\
\hline
\end{tabular}


Table 2. Cont.

\begin{tabular}{|c|c|c|c|c|c|c|}
\hline Keyword & $\begin{array}{l}\text { Individual } \\
\text { Posts } \\
\text { Frequency }\end{array}$ & Pttw & $\begin{array}{c}\text { No. } \\
\text { Texts } \\
\text { (Individual Posts) }\end{array}$ & $\begin{array}{c}\text { Institutional } \\
\text { Posts } \\
\text { Frequency }\end{array}$ & Pttw & BIC \\
\hline \multicolumn{7}{|c|}{ Neg. Kws } \\
\hline Model & 53 & 2 & 33 & 116 & 3 & 5.08 \\
\hline Findings & 27 & 1 & 21 & 91 & 3 & 14.26 \\
\hline University & 179 & 6 & 85 & 327 & 9 & 17.70 \\
\hline Colleagues & 67 & 2 & 50 & 183 & 5 & 32.16 \\
\hline Project & 32 & 1 & 24 & 122 & 3 & 34.54 \\
\hline Research & 285 & 9 & 85 & 546 & 15 & 47.24 \\
\hline Scientists & 211 & 7 & 85 & 482 & 14 & 71.48 \\
\hline Team & 44 & 1 & 27 & 255 & 7 & 132.08 \\
\hline Researchers & 81 & 3 & 50 & 384 & 11 & 173.63 \\
\hline
\end{tabular}

Table 3. Institutional vs. individual blog posts: other participant-related keywords.

\begin{tabular}{|c|c|c|c|c|c|c|}
\hline Keyword & $\begin{array}{c}\text { Institutional Posts } \\
\text { Frequency }\end{array}$ & Pttw & $\begin{array}{c}\text { No. Texts } \\
\text { (Institutional Posts) }\end{array}$ & $\begin{array}{l}\text { Individual Posts } \\
\text { Frequency }\end{array}$ & Pttw & BIC \\
\hline Researchers & 384 & 11 & 155 & 81 & 3 & 173.63 \\
\hline$N A S A$ & 118 & 3 & 43 & 13 & 0 & 73.86 \\
\hline$L a b$ & 119 & 3 & 67 & 16 & 0 & 66.06 \\
\hline Models & 72 & 2 & 33 & 15 & 0 & 22.02 \\
\hline \multicolumn{7}{|c|}{ Neg. Kws } \\
\hline You & 1.116 & 31 & 244 & 1.205 & 37 & 3.48 \\
\hline We & 1.492 & 42 & 290 & 1.708 & 53 & 28.54 \\
\hline Evidence & 179 & 5 & 93 & 300 & 9 & 29.91 \\
\hline
\end{tabular}

A few other keywords emerge by focusing on institutional blog posts and contrasting them with individual blog posts. These are reported in Table 3.

\subsubsection{First- and Second-Person Pronouns}

Individual blog posts are thus qualified by more systematic references to the firstperson singular: especially " $\mathrm{I}$ ", here including also contracted forms such as " $\mathrm{I}$ ' $\mathrm{d} /$ 'll/'m/ve", but also "my", "me", "am/'m". These certainly make both writer presence and dialogicity more conspicuous, as in the following examples:

(1) Several people, including my orthopedic specialist, have suggested that I try injections of hyaluronic acid to treat my knee pain. Many people swear by it, and even though $\underline{I}$ looked into this two years ago (and rejected it as ineffective), $\underline{I}$ thought $\underline{I}$ would look again (GEN_2015-05-18).

(2) In this column over the past few years, I've highlighted just a tiny sample of the remarkable advances coming out of the scientific world (GEN_2014-06-16).

(3) How much should we invest in biomedical research? Let me put some numbers on the table (GEN_2014-06-16).

The extracts above also exemplify important identities of the blogger. An analysis of 200 random concordances from each corpus shows, in fact, that the difference between the two datasets is also qualitative, when considering the semantic reference of personal pronouns and their collocates.

In individual blog posts, the first-person subjects co-occur very frequently with verbs indicating mental or verbal processes. The most common collocates are forms of verbs such as: "think", "read", "find", "know", "like", "say", "write", "see", "feel" (including perceptive verbs such as "see", cognitive verbs such as "know" and emotive verbs such as "like"). In institutional blog posts, the processes referred to are mostly mental-e.g., in order 
of frequency: "think", "know", read", "love", "find", "want", "believe”, "hope"—with an important role of desiderative and emotive verbs together with cognitive verbs.

When looking at the wider context, it is possible to identify the types of self that bloggers construct in their self-mentions. Adapting work carried out in the study of academic writing by Tang and John [51] and Vladimirou [52], we might say that the most prominent identities are:

- the biographical individual self (example 1);

- the blogger as writer (whether referring to the regular activity of writing as in example 2 or to the ongoing interaction as in example 3);

- the blogger as pundit, conflating Tang \& John's [51] (pp. 28-29) opinion-holdersharing "an opinion, view or attitude" —and originator-claiming authority over the main ideas and knowledge claims proposed (example 4 below);

- the blogger as academic, including both lecturer (5) and researcher (6).

(4) All told: I think this is a really, really useful book that discusses really, really important stuff (MB_2019-03-25).

(5) (Old Rag Mountain is a distinctive mountain in the eastern Blue Ridge of Virginia, contained in a little lobe of Shenandoah National Park. It's a great hike on several levels: [...], which is why I brought a group of four of my Rockies students there last Friday for a training hike (MB_2014-06-16).

(6) I like the general approach suggested in the current paper, which is to do a compatibility analysis. This is essentially what $\underline{I}$ do in an informal way-to look at all of the data analysis and ask, what kind of world are these data most compatible with? (NEU_2019-03-22).

References to the biographical self and to the blogger as writer are more evident in the corpus of individual blog posts, where they account for approximately $20 \%$ of the occurrences each. The blogger as academic (including both lecturer and researcher) is also around $20 \%$, whereas the pundit dominates with more than $30 \%$ of the occurrences being related directly to expressing an opinion.

In institutional blog posts, on the other hand, the representation of the blogger as academic (almost exclusively researcher) remains almost the same, just below 20\%, while the self as writer and the self as biographical self are reduced to 12-13\% each in favour of the self as pundit (almost 30\%). Another noticeable element is that approximately $25 \%$ of the occurrences are in reported discourse, while first-person attributed occurrences are almost unnoticeable in individual blogs.

Overall, then, the self as pundit seems to realize the constitutive identity of the blogger across corpora, but the role of the self as writer and the biographical self appears to be more conspicuous in individual blogs, whereas institutional blogs seem to provide much more room for other external voices.

Other pronouns that qualify individual blogs are first-person plural pronouns and second-person "you". The presence of an inclusive "us" in the imperative form "let's" guides the reader through the argument and thus belongs more properly to what we might call action-oriented dialogicity (see below); the first-person plural "we", on the other hand, often occurs in clusters within specific explanatory moves, frequently mixing inclusive "we" with generalized reference:

(7) In the Copenhagen interpretation, as we have seen, the behavior of a quantum particle or particles is truly random: [...] we don't usually measure, or know how to measure, all the variables that decide whether a coin comes up heads or tails (SKU_2017-05-06).

Finally, while acknowledging the undoubtedly major role of generalized "you" in scientific argument and demonstration, individual blog posts are characterized by a richness of direct addresses to the audience. Here, for example, the audience is invited to write "geopoetry" as an educational activity for geology students:

(8) As you'll see, I wasn't entirely able to get away from jargon (and in fact, the toothsome flavor of geology words is one of the reasons it's so fun to write about, as John McPhee has noted), but I did manage to come up with a few new ways of describing geologic actions. See what you 
think. If you write any geopoetry (a phrase popularized by Harry Hess) of your own, I hope you'll post a link to it in the comments below (MB_2016-09-19).

\subsubsection{The Scientific Community}

If the difference in the use of personal pronouns is hardly surprising, variation in the representation of the interlocutors of the blogger is more interesting. References to texts as repositories of ideas or evidence to be discussed are altogether extremely common: “book(s)", “titles", "post(s)", “article", “writing", "evidence", “blog", “website" account for a good many references to sources quoted, often evoked also by deictic reference ("this", "here"):

(9) And just last summer, Robert F. Kennedy Jr. published a new book further promoting the long-discredited claim that thimerosal causes autism (GEN_2015-02-01).

(10) For an excellent summary of NCCIH's history, see this short video from Reason TV or my own talk from a 2015 conference, here (GEN_2018-01-08).

Individual blogs thus do not only give more space to the blogger and great prominence to their biographical self and their academic self interacting with readers, they also highlight the position of bloggers in a constant debate with sources and scholarly production, as members of the discourse community.

Institutional blogs, on the other hand, favour explicit reference to the process of inquiry ("model", "findings") and the representation of science as collective work with plural categories ("researchers", "team", "scientists", "colleagues") or collective nouns ("team", "NASA", "FDA", "lab", "project"), while they are more limited in the use of "college", a word often used to identify the educational component of the academic context. The greater frequency of plural or collective categories of researchers contributes to both general reference to the background of the world of science and specific reference to a particular paper or discovery:

(11) For decades, researchers had identified gallium nitride as a material that could potentially produce blue light very efficiently, but huge technological problems, which seemed insurmountable at times, stood in the way of a practical consumer device (PHY_2014-10-06).

(12) A team of researchers at the Technical University of Denmark's (DTU) Nanotech and Fotonik departments has innovated a new laser-printing technology that is able to achieve a resolution of 127,000 dots per inch (PHY_2016-01-07).

Overall, then, institutional blog posts do not only reveal a less personal, more formal representations of science, but also a clearer emphasis on its collaborative nature. The small set of 4-word clusters obtained by contrasting the two corpora confirms the key role played by representatives of the discourse community in institutional blog posts, given the high frequency of "at the university of" (75 occurrences of in 54 texts ( 2 pttw) vs. 16 occurrences in 15 texts in individual blogs). The expression is mostly used to introduce specific scientists whose research is reported (13), but occasionally also includes a few background generic references (14) and even one first-person report (15):

(13) "By the end of the Devonian, there were vertebrates that were quite at home moving around on land," said Balbus, who is at the University of Oxford in the United Kingdom (PHY_201406-30).

(14) In 2013, scientists at the University of St. Andrews made headlines by propelling a tiny sphere to a record-breaking 600 million rpm (revolutions per minute) (PHY_2018-09-10).

(15) Five years later, I worked part-time in a lab at the University of Texas cultivating strains of algae that naturally accumulate oil (PLOS_SB_2015-09-08).

In terms of participant-related dialogicity, then, the analysis of keywords and keyphrases has shown that institutional blogs tend to favour patterns of attribution, with the blogger reporting scientific discoveries and debates and third-person researchers occupying centre stage. Individual blogs, on the other hand, tend to favour reference to the direct participants, thus highlighting the identity of the blogger in terms of their biographical and academic self. 


\subsubsection{The Representation of Discourse within the Community}

Tables 4 and 5 provide a list of the keywords that qualify the verbal processes in the debate the post is contributing to (e.g., "claim"). As previously stated, Table 4 lists all the elements obtained, focusing on individual posts and using institutionalized blog posts as reference corpus, while Table 5 adds a few other keywords obtained focusing on institutional blog posts and using blog posts for reference. As already noted, these reflexive elements can often cut across perspectives. Forms of the verb "note", for example, can be seen to serve very different functions: they can be used to describe what reported authors do ("he noted"), to attract the reader's attention with an imperative ("note that"), and to structure the development of the text through expressions such as "as noted previously", "I also noted", "it should be noted", etc. The various verbal forms (and their nominalizations) are presented under the heading that proved to be dominant in a concordance analysis.

Table 4. Attribution and the representation of discourse in individual blogs.

\begin{tabular}{ccccccc}
\hline Keywords & $\begin{array}{c}\text { Individual Posts } \\
\text { Frequency }\end{array}$ & Pttw & Texts & $\begin{array}{c}\text { Institutional Posts } \\
\text { Frequency }\end{array}$ & Pttw & BIC \\
\hline Claims & 144 & 4 & 58 & 14 & 0 & 123.60 \\
Claim & 99 & 3 & 61 & 19 & 1 & 53.78 \\
Written & 91 & 3 & 68 & 24 & 0 & 34.74 \\
Wrote & 96 & 3 & 65 & 31 & 0 & 27.86 \\
Claimed & 26 & 1 & 24 & 1 & 0 & 17.86 \\
Claiming & 34 & 1 & 29 & 4 & 0 & 16.58 \\
Argued & 32 & 1 & 19 & 4 & 0 & 14.07 \\
Noted & 65 & 2 & 43 & 23 & 1 & 11.60 \\
Stories & 61 & 2 & 34 & 22 & 1 & 9.49 \\
Writing & 69 & 2 & 52 & 29 & 0 & 7.36 \\
Recommend & 30 & 1 & 28 & 6 & 0 & 6.37 \\
Write & 64 & 2 & 42 & 29 & 1 & 3.57 \\
\hline & & & Neg. Kws & & & \\
\hline Explains & 27 & 1 & 27 & 73 & 3 & 4.44 \\
Response & 36 & 1 & 28 & 103 & 9 & 79.70 \\
Said & 99 & 3 & 73 & 307 & 48 & 316.47 \\
Says & 62 & 2 & 42 & 482 & \\
\hline
\end{tabular}

Table 5. Institutional vs. individual blog posts: other elements.

\begin{tabular}{ccccccc}
\hline & $\begin{array}{c}\text { Institutional Posts } \\
\text { Frequency }\end{array}$ & Pttw & Texts & $\begin{array}{c}\text { Individual Posts } \\
\text { Frequency }\end{array}$ & Pttw & BIC \\
\hline $\begin{array}{c}\text { Responses } \\
\text { Studying }\end{array}$ & 37 & 1 & 22 & 4 & 0 & 14.18 \\
\hline & 57 & 2 & 51 & 15 & 0 & 8.90 \\
\hline Story & 86 & 2 & 54 & 155 & 5 & 13.63 \\
Notes & 107 & 3 & 46 & 13 & 0 & 62.03 \\
\hline
\end{tabular}

In the representation of verbal action, verbal forms such as "written", "wrote", "writing" and "write" typically describe the activity of the blogger and the academic community:

(16) For years, scientists (including me) have warned that the anti-vaccination movement was going to cause epidemics of disease. Two years ago I wrote that the anti-vaccine movement had caused the worst whooping cough epidemic in 70 years. And now it's happening with measles (GEN_2015-02-01).

What is most interesting in individual blogs, however, is that the representation of academic debates often refers to their argumentative nature and to patterns of claiming and counterclaiming. The process is represented as one of noting ("notes") but above all claiming and arguing ("claim/s/ed/ing", "argument/s") (example 17) or even recommending 
("recommend"). Another important dimension mentioned explicitly is that of storytelling; mention of "stories" is actually quite common in reviews and references to fake news and conspiracy theories (examples 18 and 19):

(17) After the lawsuit, Airborne modified their packaging, which now claims only that it "helps support your immune system." This is one of those vague claims that supplement makers love, because it doesn't really mean anything (GEN_2014-11-17).

(18) The most dramatic stories occur in the first 2/3rds of the book, which cover World War II and then the initial and dangerous tests of hypersonic rocket aircraft (SKU_2016-08-16).

(19) Stories take on a life of their own. That is the origin of urban legends, myths, and even religion. A good narrative feeds on itself and can be self-sustaining. It evolves and adapts and finds fertile ground in most human hosts (unless they have been inoculated with a sufficient dedication to facts and logic) (NEU_2016-11-15).

Institutional discourse, on the other hand, prefers more neutral representations of verbal processes, mostly characterized by verbs of locution such as "say" and "note" (20), or references to topic-setting illocutionary functions such as 'explaining' and 'studying'. These references to verbal processes often make up long chains of representations (21) where the actual reporting is mostly realized in non-interpretative terms:

(20) "What we see in the great apes, and in corvids [the family of birds that includes crows], and in dolphins, and in elephants, is the social complexity in their lives," says Andrews. As an example, she cites the grieving behavior of elephants following the death of a relative: Elephants "will go back year after year and caress the bones of dead ancestors," she says, and notes that dolphins and chimpanzees display a similar behavior (DISC_TC_2014-12-05).

(21) Brian Nosek, a psychologist at the University of Virginia in Charlottesville who ran the Many Labs 3 Project, thought the new study was a nice reuse of existing data. "We did not design that study to test ego depletion, but the authors discovered there's a manipulation that's common for ego depletion," Nosek says. "I thought it was a creative application of data re-analysis." But while the original studies on ego depletion did use a Stroop task and an anagram task, notes Greg Walton, a social psychologist at Stanford University, that doesn't mean that ego depletion was the phenomenon that ended up being tested. "The assumption in the paper is that doing the Stroop test first would be depleting," he explains (SN_S_2018-12-16).

Overall, then, the representation of community discourse is mostly related to arguing and storytelling in individual blogs, whereas it is reported in more neutral terms, mostly referring to basic locutionary roles, in institutional blogs.

\subsection{Action-Oriented Dialogicity}

The central tools of action-oriented dialogicity are meta-statements and organizational units at different levels. Table 6 provides a list of the relevant keywords, lexical elements that can play a major role in representing the development of the text and the interaction that is taking place through the text.

The keywords thus identified can be grouped basically along two lines: lexical elements that mark the development of the text ("conclusion") and elements characterizing reader engagement ("let's").

Reader Engagement is typically represented by imperatives, questions and directions ("let/let's", "read", "here's", "note", "notice"). These frequently represent the blogger as writer guiding the reader through the development of the argument (22), introducing the topic and the text under examination (23) or adding an aside (24) and guiding the reader through observation (25):

(22) Let's suppose a bunch of scientists proposed to take one of the most infectious human virusesinfluenza, say-and turn it into a super-bug. Is this a good idea? (GEN_2014-10-20).

(23) Homeopaths did it again-they snuck a dubious study into a respectable journal. Well, sort of. Let's quickly look at the study, and then look at the journal that published it (GEN_2018-10-15). 
(24) What was much more surprising, and deeply disappointing, was the response of candidate Ben Carson, who until last year was a pediatric neurosurgeon at Johns Hopkins School of Medicine. (Note that although I too work at Hopkins Medicine, I've never met Dr. Carson.) (GEN_2016-09-20).

(25) Did you notice the bonus glacial striations in that last shot (on the left)? (MB_2018-06-23).

Table 6. Action-oriented dialogicity: individual vs. institutional blog posts.

\begin{tabular}{ccccccc}
\hline Keyword & $\begin{array}{c}\text { Institutional Posts } \\
\text { Frequency }\end{array}$ & Pttw & Texts & $\begin{array}{c}\text { Individual Posts } \\
\text { Frequency }\end{array}$ & Pttw & BIC \\
\hline Let & 176 & 5 & 107 & 75 & 2 & 38.44 \\
Conclusion & 77 & 2 & 37 & 15 & 0 & 38.32 \\
Interpretation & 48 & 1 & 21 & 4 & 0 & 37.41 \\
Read & 195 & 6 & 110 & 93 & 3 & 33.72 \\
Let's & 53 & 2 & 40 & 9 & 0 & 25.43 \\
Here's & 41 & 1 & 35 & 5 & 0 & 22.20 \\
Argument & 67 & 2 & 39 & 23 & 1 & 13.37 \\
Note & 98 & 3 & 75 & 45 & 1 & 11.99 \\
Arguments & 34 & 1 & 23 & 7 & 0 & 8.56 \\
Therefore & 94 & 3 & 58 & 47 & 1 & 7.27 \\
Statement & 50 & 2 & 32 & 20 & 1 & 2.83 \\
Notice & 34 & 1 & 28 & 10 & 0 & 2.76 \\
Examples & 42 & 1 & 36 & 15 & & 2.55 \\
\hline & & & Neg. Kws & & 9 & 8.41 \\
\hline While & 186 & 6 & 132 & 313 & 14 & 10.62 \\
How & 556 & 17 & 215 & 790 & 5 & 10.80 \\
Such & 311 & 10 & 148 & 486 & 5 & 32.95 \\
Whether & 76 & 2 & 54 & 162 & \\
Although & 60 & 2 & 53 & 172 & & 0 \\
\hline
\end{tabular}

As we have seen, reference to discursive processes is actually often nominalized, and metadiscursive labelling nouns ("interpretation", "conclusion") act as cohesive (anaphoric or cataphoric elements) (26 and 27). The key role of labelling nouns in representing discourse and counter-discourse often builds up the main line of argument; as shown in (28):

(26) Something is definitely wrong with the uniformitarian story-why else would scientists be so surprised by the black rock and marine fossils? Could it be that all these strata-the red and black rocks - are deposits from the great Flood? This interpretation eliminates the mystery of how marine fossils are found sandwiched in between red sands and shale (MB_2014-03-18).

(27) I present the structure as a fault-propagation fold, and in the second image I add my interpretation: the position of the fault changes from parallel to layering to where it ramps up and cuts across the footwall strata into the hinge of the syncline (MB_2019-02-24).

(28) GMWatch, an anti-GMO organization, published a lengthy response to the Nobelists' letter the day after the letter appeared. Their rebuttal contains two arguments: first, that [...]; and second, that [...]. Hmm. Neither of these arguments stands up to even a tiny bit of scrutiny. First, [...] Second, the argument about relevant expertise is ridiculous. [...] I also have to point out that this is a classic ad hominem attack: [...] (GEN_2016-07-04).

The only other cohesive element that features in individual blog posts is in fact "therefore", a clear marker of conclusion. The other connectors found in the keyword list ("while", "how", "such", "whether", "although") are preferably used in institutional blog posts to report debate, pointing at a multiplicity of positions to be balanced in concessive patterns ("while", "although") rather than at the line of argument that supports one position:

(29) While recent reports demonstrate that most low and middle-income countries have increased government health expenditure over the past decade, experts agree that it is overly optimistic to translate this into a model of autonomous national health spending without external support for the foreseeable future (PLOS_SoM_2015-07-13). 
Organizational units are best illustrated in the study of 4-word clusters. Individual blog posts are characterized by action-oriented clusters that involve both elements of reader engagement and metatextual organization, all of which have no occurrences in the corpus of institutional blogs: "it should be noted" (12 occurrences), "can be read here" (12), "as you can see" (11), "take a look at" (11). An example is reported below:

(30) Massive diamictites may be due to glacial deposits or to debris flows, but dropstones are a surer indication of glaciation. However, it should be noted that these strata are Devonian, and that plants had evolved by the Devonian (MB_2015-12-08).

The only other 4-word cluster found that could be attributed to action-oriented dialogicity is the temporal organizational unit "for the rest of" (14 occurrences vs. none), often followed by 'reversals' introducing important changes in the plot of the narrative:

(31) Mayer returned to his hometown of Heilbronn in early 1841 and set up a medical practice there; this would be his main profession for the rest of his life. But he realized that he had discovered something profound about nature, and immediately began writing up his work for publication (SKU_2018-12-28).

Once again, the analysis of key words and key-phrases points at stronger reader engagement in individual blog posts, with greater use of metatextual elements that highlight the argument and the narrative, while institutional posts are characterized by connectors introducing explanations and balancing diverse positions in concessive patterns.

\subsection{Evaluative Dialogue}

The set of keywords pointing to evaluative dialogue includes explicit evaluative language - expressing epistemic assessments, attitudinal assessments or markers of relevance $[43,44]$ - and other markers, such as negative elements, that typically position the reader in terms of acknowledging or rejecting the need to negotiate topics and positions. Tables 7 and 8 list the elements that were found to play a role in this process, including all the elements found when focusing on individual blog posts in Table 7 and those found only when focusing on institutional blog posts in Table 8.

An overall consideration of the keywords suggests that evaluative dialogue is richer in individual blog posts. These are characterized first of all by an intense use of contracted negative elements ("don't", "doesn't", "didn't", "nothing", "cannot", "none", "can't", "hasn't", "not"). Negation is arguably "a resource for introducing the alternative positive position into the dialogue, and hence acknowledging it, so as to reject it" [45] (p. 118). Negative forms are often used to clarify and contrast positions, especially in opening or conclusive statements:

(32) Now, the fact that Bérard has previously testified in court cases doesn't prove that her current study is flawed, but it does indicate that she has a bias against antidepressants. This bias might explain why her study looked so hard to find an effect when the data don't seem to support it (GEN_2015-12-21).

Another important set of lexical elements can be classified as evaluative attitudinal language clearly ranging from negative to positive ("lovely", "nonsense", "beautiful", "novel", "nice", "misleading", "excellent", "bad"). These highlight the central role of praise and criticism in the structure of these posts. The following extract provides an example, also showing how all the elements of evaluative dialogue are interrelated: explicit attitudinal evaluation ("misleading" and "ploy"), denial ("has not been evaluated") and epistemic assessment ("could step in" vs. "they've already done").

(33) Zicam's website makes the misleading claim that "All of our Zicam ${ }^{\circledR}$ products are regulated by the FDA." This is a common ploy of homeopathic drugmakers, claiming the FDA regulates them because the FDA could step in (as they've already done with Zicam) if consumers are being harmed. Unlike real drugs, though, Zicam has not been evaluated by the FDA for effectiveness or safety (GEN_2014-11-17). 
Table 7. Elements of evaluative dialogue: individual vs. institutional blog posts.

\begin{tabular}{|c|c|c|c|c|c|c|}
\hline & $\begin{array}{l}\text { Individual Posts } \\
\text { Frequency }\end{array}$ & Pttw & Texts & $\begin{array}{l}\text { Institutional Posts } \\
\text { Frequency }\end{array}$ & Pttw & BIC \\
\hline Don't & 123 & 4 & 67 & 26 & 1 & 64.62 \\
\hline Apparently & 97 & 3 & 67 & 14 & 0 & 64.37 \\
\hline Doesn't & 77 & 2 & 45 & 10 & 0 & 51.60 \\
\hline Simply & 140 & 4 & 89 & 45 & 1 & 47.10 \\
\hline Lovely & 56 & 2 & 38 & 7 & 0 & 34.70 \\
\hline Risk & 230 & 7 & 59 & 118 & 3 & 34.57 \\
\hline Nonsense & 32 & 1 & 25 & 0 & 0 & 34.01 \\
\hline Seems & 149 & 5 & 98 & 67 & 2 & 26.68 \\
\hline Beautiful & 60 & 2 & 39 & 14 & 0 & 21.86 \\
\hline False & 67 & 2 & 35 & 18 & 1 & 21.43 \\
\hline Didn't & 40 & 1 & 35 & 5 & 0 & 20.95 \\
\hline Novel & 109 & 3 & 35 & 45 & 1 & 20.35 \\
\hline Must & 163 & 5 & 80 & 88 & 2 & 16.93 \\
\hline Perhaps & 129 & 4 & 98 & 67 & 2 & 12.79 \\
\hline True & 137 & 4 & 80 & 75 & 2 & 11.27 \\
\hline Nothing & 105 & 3 & 80 & 51 & 1 & 11.08 \\
\hline Obvious & 47 & 1 & 35 & 13 & 0 & 10.36 \\
\hline Misleading & 26 & 1 & 21 & 3 & 0 & 9.71 \\
\hline Nice & 58 & 2 & 48 & 21 & 1 & 8.25 \\
\hline Excellent & 46 & 1 & 38 & 14 & 0 & 7.70 \\
\hline Cannot & 75 & 2 & 57 & 33 & 1 & 7.53 \\
\hline Compelling & 40 & 1 & 28 & 11 & 0 & 6.93 \\
\hline Basically & 45 & 1 & 38 & 14 & 0 & 6.75 \\
\hline Overall & 73 & 2 & 53 & 33 & 1 & 6.04 \\
\hline Can & 1.041 & 32 & 285 & 1.362 & 38 & 4.71 \\
\hline None & 55 & 2 & 40 & 22 & 1 & 4.45 \\
\hline Can't & 32 & 1 & 21 & 8 & 0 & 4.34 \\
\hline Literally & 26 & 1 & 26 & 5 & 0 & 4.20 \\
\hline Supposed & 35 & 1 & 28 & 10 & 0 & 3.73 \\
\hline Facts & 40 & 1 & 28 & 13 & 0 & 3.65 \\
\hline Reasonable & 40 & 1 & 27 & 13 & 0 & 3.65 \\
\hline Bad & 84 & 3 & 60 & 44 & 1 & 3.33 \\
\hline \multicolumn{7}{|c|}{ Neg. Kws } \\
\hline Happen & 35 & 1 & 31 & 74 & 2 & -2.59 \\
\hline Needed & 34 & 1 & 28 & 73 & 2 & -2.31 \\
\hline Important & 119 & 4 & 80 & 196 & 6 & -0.96 \\
\hline Suggests & 30 & 1 & 25 & 70 & 2 & -0.51 \\
\hline Enough & 117 & 4 & 83 & 199 & 6 & 1.08 \\
\hline Suggest & 28 & 1 & 25 & 72 & 2 & 2.69 \\
\hline Might & 268 & 8 & 155 & 403 & 11 & 2.71 \\
\hline Can & 1.041 & 32 & 285 & 1.362 & 38 & 4.71 \\
\hline Around & 183 & 6 & 113 & 308 & 9 & 8.08 \\
\hline Potential & 64 & 2 & 41 & 168 & 5 & 25.63 \\
\hline May & 285 & 9 & 150 & 515 & 14 & 33.78 \\
\hline Could & 341 & 11 & 154 & 785 & 22 & 127.23 \\
\hline
\end{tabular}

If elements of negation and of attitudinal assessment become prominent in individual blog posts only, epistemic assessments (expressions of certainty and probability) qualify both corpora. Individual posts, however, present a much wider range of degrees of certainty/probability, often including extremes that tend to dialogic contraction (34), while institutional posts are mostly defined by degrees of tentativeness and dialogic expansion (35):

(34) So go ahead, drink your raw milk and eat a paleo diet too, while you're at it. But don't ask our modern medical system to pay for your treatment when you get sick. And most of all, don't subject innocent children to the unnecessary risks of raw milk (GEN_2014-04-07). 
(35) Mars was once a wetter world, and according to a growing body of evidence, could have had water gushing through rivers, pooling in lakes and possibly even oceans (PHY_2014-03-31).

Table 8. Institutional vs. Individual blog posts: other elements of evaluative dialogue.

\begin{tabular}{|c|c|c|c|c|c|c|}
\hline Keyword & $\begin{array}{l}\text { Institutional Posts } \\
\text { Frequency }\end{array}$ & Pttw & Texts & $\begin{array}{l}\text { Individual Posts } \\
\text { Frequency }\end{array}$ & Pttw & BIC \\
\hline Expected & 63 & 2 & 54 & 21 & 0 & 4.78 \\
\hline \multicolumn{7}{|c|}{ Neg. Kws } \\
\hline Hasn't & 28 & 0 & 23 & 1 & 0 & 15.60 \\
\hline Very & 295 & 8 & 165 & 407 & 13 & 16.60 \\
\hline Good & 173 & 5 & 113 & 268 & 8 & 17.10 \\
\hline Should & 215 & 6 & 122 & 318 & 10 & 17.46 \\
\hline Not & 1.176 & 33 & 328 & 1.404 & 43 & 33.89 \\
\hline
\end{tabular}

The key 4-word-clusters characterizing individual blog posts include two clusters revolving around the verb "turn out": "turn out to be" and "turns out that". The first cluster"turn out to be" (15 occurrences) - is followed by predicates that are often comparative or refer to successive interpretations of facts: "other viruses" / "something else" / "true" (2)/"just a pose" /"on the whole sane" /"a big deal" / "safe and effective" / "false" / "wrong" /"somewhat less spectacular" /"useful" /"the chance of a lifetime" / "quite prophetic" / "due to quantum effects", as in example (36). The cluster "it turns out that" (12 occurrences) also connects contrastive or contradictory statements while showing that something proves to be true/false against all expectations, as in example (37).

(36) Lovecraft's laymen's view of astronomy would turn out to be quite prophetic (SKU-2016-11-20).

(37) When looking at the effect of gravity on the wave properties of matter, however, something strange happens. It turns out that the wave properties depend explicitly on the mass of the particle divided by Planck's constant, known as "h-bar." (SKU_2015-05-20).

When looking at key-clusters, then, individual blog posts appear to be characterized by the narrative voice of the blogger, who constructs sequences of unexpected reversals in the process of discovery. The patterns created by the various constructions of "turn out" highlight the dynamicity of ever-changing perspectives on science that invariably prove to be confirmed or disconfirmed by later views. Emphasis is placed on an unexpected change in perspective and on a narrative of science that creates sequences of conflicts and resolutions, where facts are interpreted and reinterpreted.

In institutional blog posts, on the other hand, evaluative dialogue is represented by 24 occurrences (in 24 texts) of "is one of the", totally absent in the other corpus. This constitutes the kernel of an identification sentence typically introducing (often comparative) evaluative expressions such as "hardest features", "best things", "most fascinating developments", "many reasons", "world's rarest lifestyles", etc.

(38) Magnesium is one of the lightest metals on the periodic table (PHY_2018-03-27).

The only other evaluative element to be noticed is "will be able to", characterizing moves that explore the implications of discoveries or events announced:

(39) Going back through the Landsat archive didn't reveal any big changes in penguin diet, but now researchers will be able to monitor it as the region changes and provide real data to Antarctic ecosystem managers (SN_WT_2019-01-02).

What becomes dominant in institutional blogs is the voice of the blogger taking position as to the facts he or she introduces, by assessing their importance or presenting the implications. The voice of the blogger is less explicit in expressing opinions but more careful in guiding the readers towards forming an opinion. 


\section{Conclusions}

The qualitative analysis of quantitative data has confirmed the importance of looking at different aspects of dialogicity when studying variation across individual and multiauthored blogs. It has also hopefully shown that the complex set of elements that constitute dialogicity can contribute to defining how bloggers manage subjective and intersubjective positioning and construct their credibility in ways that also define the nature of their relation to the audience and ultimately to the functions of blogging.

The study of participant-oriented markers has confirmed that individual blogs (unsurprisingly) favour reference to the first- and second-person pronouns. The greater prominence of the personal identity of the blogger is also accompanied by qualitative differences: individual blogs highlight the biographical self of the blogger and their writer self, while also making the identity of the academic more clearly linked to the educational dimension; institutional blogs tend to favour patterns of attribution. The qualitative difference thus proves to be more interesting than the quantitative: individual blogs produce more personal, idiosyncratic writing and construct an authorial identity that emphasizes biographical elements of the blogger, while institutional blogs construct a more neutral identity of the blogger as expert in research, typically balancing the voice of the blogger with the collective voice of other researchers and offering a wider picture of the debate within the community.

The representation of dialogue within the community turns out to be a relevant distinctive element. Institutional blogs tend to favour a wider representation of communicative action, but one that is largely limited to the most neutral forms of reporting, mostly referring to basic locutionary roles. Individual blogs give greater prominence to storytelling and to the role of the blogger's argument (i.e., to patterns of claiming and counterclaiming), highlighting the position of bloggers in debate with sources as members of the discourse community. In both cases, blogs allow for a representation not only of the blogger's position but also of a debate with a range of positions. What changes is rather the role of the blogger: more explicitly interacting with the sources in one case and rather preoccupied of accurately reporting the range of positions in the other.

Similarly, action-oriented forms of dialogicity offer a picture of individual blogs emphasizing writer-reader direct argumentative dialogue, with institutional blogs presenting a more expositive position. Individual blogs present a more marked preference for reader engagement, with greater use of metatextual elements that highlight the argument and the narrative, while institutional posts are characterized by connectors introducing explanations and balancing diverse positions in concessive patterns. In some way, the representation of dialogue within the community and the representation of dialogue with the reader appear to converge: they both suggest greater emphasis on disseminating knowledge content in institutional blogs and greater emphasis on bonding and bridge building (as well as self-branding) in individual blogs.

What is most important, given the key role of evaluative language in blogs, is the way bloggers construct an evaluative dialogue with their readers. Evaluative dialogue is much more clearly highlighted in individual than institutional blogs when looking at quantitative data. Institutional blogs tend to feature more careful epistemic expressions, mostly testifying degrees of tentativeness and forms of dialogic expansion, assessing the importance of facts reported, presenting implications and guiding the readers towards forming their own opinion. Individual blogs, on the other hand, are characterized by a wide range of evaluative elements: negative forms used to clarify and contrast positions, attitudinal items expressing praise and criticism and a wide range of epistemic markers often including extremes that tend to dialogic contraction. Evaluative dialogue thus further contributes to highlighting different functions of blogs-bonding and self-branding in individual blogs vs. knowledge dissemination in institutional blogs.

The analysis thus confirms the expectation that blogs managed by individual scientists emphasize personal, narrative and argumentative voice together with interpersonal elements, while institutional blogs are comparatively more neutral and informational. It also 
points, however, towards a distinction that involves much more than the relative presence of personal elements. By linking self-mention to the representation of the community and of writer-reader interaction with a special focus on evaluative dialogue (and how evaluation contributes to subjective and intersubjective positioning), the study also reflects how different language markers could point to different general functions often attributed to blogs: outreach and self-branding.

It should be noticed, of course, that the distinction between bloggers' identities in the two datasets is not just a matter of individual vs. collective identity, as individual and collective identities are always present in both contexts. An important factor could be that writer voice in institutional blogs may be influenced by the presence of the institution itself as website "principal" (Goffman 1981), taking responsibility for the web space that hosts the blog, and superimposing less personal forms of authoritativeness. The credibility and reputation of the institution somehow reflects on the individual voice, possibly having an impact on the peculiar combination of authorial voices found in the two corpora: the voice of the pundit is constitutively dominant but it leaves greater room for the biographical self and the academic lecturer in individual blogs, while emphasizing the researcher and the dialogue between researchers in the community in institutional blogs.

What becomes evident is that the multiplicity of voices involved in institutional blogs and the multiplicity of identities manifested by individual bloggers determine noticeable variation across these two types of 'scientific blogs'. The presence of more or less personal forms of voice confirms the prominence of writer identity(/ies) in blogs: while blogs often blur the distinction between expert and non-expert audiences [4], they seem to maintain the need to manifest the self of the blog(-ger) in the different forms that may be relevant to establishing credibility and trust. The credibility of the individual scholar seems to rely on different elements in the two types of blogs. On the one hand, in institutional blogs the voice of the blogger relies on the authoritativeness of more neutral language and probably thrives on the authoritativeness of the institution. On the other hand, individual bloggers deliberately avoid the neutral and objective language typically associated with the discourse of science, blurring their private and public identities and variously relying on the credibility of an academic self or on the trust inspired by a private ("ordinary person") persona.

In a general climate of public distrust in experts and science, scientists may thus tend to make recourse to two basic strategies: adopting the more neutral stance of journalistic reporting or collapsing their public and private personae to shift the discourse plane to personal "one-to-one" interaction. The representation of authorial identity, however, is only fully understood within the framework of the representation of the debate within the community and the representation of writer-reader interaction. It is only by looking at the full range of elements that we can see how the blogger and the reader are positioned as to the issue at hand and the wider debate, as well as how they are oriented to outreach or reputation management.

The study presented here clearly has a number of limitations, primarily related to the corpus and to the methodology. The corpus is quite obviously limited and almost inevitably not really balanced from a disciplinary point of view: as the idea behind the development of the corpus was to make it comparable to other disciplinary fields (e.g., the social sciences) and to explore the comments as well, the corpus is limited in size and the analysis could be confirmed or disconfirmed by working on a different set of blogs. When comparing individual and multi-authored blogs, moreover, disciplinary interests are also obviously varied. A focus on disciplinary argument would require a totally different set of blogs, maybe developed around a specific topic and comparing an equal number of bloggers who write for their own blogs or for multi-authored institutional blogs. Along the same lines, it would be interesting to develop a comparison between a wider set of multi-authored blogs connected to disciplinary organizations and blogs connected to popularizing magazines, to observe if there is variation in the representation of scientific communities. The methodology adopted-starting from word forms that are statistically 
more or less frequent in one corpus than in the other-also has its limitations as it tends to highlight differences between the two subsets. A more specific study of each blog might reveal other interesting elements of commonality or divergence. Finally, given the key role played by reader engagement and evaluative dialogue in defining the nature of the two types of blogs, a closer study of these two perspectives might further illuminate their respective contribution to the distinction between these two types of blogs and to how they contribute to outreach and/or reputation management. Hopefully, however, the study has provided a basis for further exploration of the nature of research blogs and their role within the system of options available for science communication.

Funding: This research was funded by the Italian Ministry of Research, grant number PRIN 2015protocollo: 2015TJ8ZAS.

Data Availability Statement: This publication is based upon corpus data collaboratively developed by PRIN 2015TJ8ZAS members. Data are available on request from: http:/ / dolly.2016.unimore.it/ dslc/ course/view.php?id=345 (accessed on 20 January 2022).

Acknowledgments: I would like to thank the anonymous reviewers for their useful suggestions and comments.

Conflicts of Interest: The author declares no conflict of interest.

\section{Notes}

1 http:/ / www.fieldofscience.com/p/about.html (accessed on 20 January 2022).

\section{References}

1. Herring, S.; Stein, D.; Virtanen, T. Pragmatics of Computer-Mediated Communication; De Gruyter: Berlin, Germany, 2013. [CrossRef]

2. Myers, G. The Discourse of Blogs and Wikis; Continuum: London, UK, 2010; ISBN 13 978-1847064141.

3. Barton, D.; Lee, C. Language Online. Investigating Digital Texts and Practices; Routledge: London, UK, 2013 ; ISBN 9780415524957.

4. Schmidt, J.-H. Blogging Practices: An Analytical Framework. J. Comput. Commun. 2007, 12, 1409-1427. [CrossRef]

5. Kjellberg, S. I am a Blogging Researcher: Motivations for Blogging in a Scholarly Context. First Monday Peer-Rev. J. Internet 2010, 15, 2010. Available online: http:/ / firstmonday.org/ojs/index.php/fm/article/view/2962/2580 (accessed on 20 January 2022). [CrossRef]

6. Herring, S.C.; Scheidt, L.; Wright, E.; Bonus, S. Weblogs as a bridging genre. Inf. Technol. People 2005, 18, 142-171. [CrossRef]

7. Miller, C.; Shepherd, D. Blogging as Social Action: A Genre Analysis of the Weblog. In Into the Blogosphere: Rhetoric, Community and the Culture of Weblogs; Gurak, L., Antonijevic, S., Johnson, L., Ratliff, C., Reyman, J., Eds.; University of Minnesota Press: Minneapolis, MN, USA, 2004; Available online: https:/ /hdl.handle.net/11299/172818 (accessed on 20 January 2022).

8. Santini, M. Some Issues in Automatic Genre Classification of Web Pages. In Proceedings of the JADT 2006: 8es Journées Inter-nationales d'Analyse Statistique des Données Textuelles, Besançon, France, 19-21 April 2006; pp. 865-876.

9. Tomášková, R. "And this is the view from outside my window": On text and image interplay in university website blogs. Top. Linguist. 2017, 18, 81-93. [CrossRef]

10. Kuteeva, M. Research Blogs, Wikis and Tweets. In The Routledge Handbook of English for Academic Purposes; Hyland, K., Shaw, P., Eds.; Routledge: London, UK, 2016; pp. 431-443.

11. Baron, N. Always On: Language in an Online and Mobile World; Oxford University Press: Oxford, UK, 2008; ISBN 13-978-0199735440.

12. Luzón, M.J. 'Interesting Post, But I Disagree': Social Presence and Antisocial Behaviour in Academic Weblogs. Appl. Linguist. 2011, 32, 517-540. [CrossRef]

13. Luzón, M.J. "Your argument is wrong": A contribution to the study of evaluation in academic weblogs. Text Talk 2012, 32. [CrossRef]

14. Luzón, M.J. Public Communication of Science in Blogs: Recontextualizing Scientific Discourse for a Diversified Audience. Writ. Commun. 2013, 30, 428-457. [CrossRef]

15. Barton, D.; McCulloch, S. Negotiating tensions around new forms of academic writing. Discourse Context Media 2018, 24, 8-15. [CrossRef]

16. Hynninen, N. Impact of digital tools on the research writing process: A case study of collaborative writing in computer science. Discourse Context Media 2018, 24, 16-23. [CrossRef]

17. Weitkamp, E.; Milani, E.; Ridgway, A.; Wilkinson, C. Exploring the digital media ecology: Insights from a study of healthy diets and climate change communication on digital and social media. J. Sci. Commun. 2021, 20, A02. [CrossRef]

18. Samuel, A. Have LinkedIn and Medium Killed the Old-Fashioned Blog? Harvard Business Review. 30 June 2015. Available online: https:/ /hbr.org/2015/06/have-linkedin-and-medium-killed-the-old-fashioned-blog (accessed on 20 January 2022). 
19. Mohamed, F. The Rise and Fall of the Blog. JSTORDaily. 27 December 2017. Available online: https://www.jstor.org/the-riseand-fall-of-the-blog-/ (accessed on 20 January 2022).

20. Sánchez-Villar, J.M. The use of blogs as social media tools of political communication: Citizen journalism and public opinion 2.0. Commun. Soc. 2019, 32, 39-55. [CrossRef]

21. Crestodina, A. New Blogging Statistics: Survey of 1067 Bloggers Shows Which Content Strategies are Working in 2021. Available online: https:/ / www.orbitmedia.com/blog/blogging-statistics/ (accessed on 20 January 2022).

22. Mewburn, I.; Thomson, P. Towards an academic self? Blogging during the Doctorate. In The Digital Academic Critical Perspectives on Digital Technologies in Higher Education; Lupton, D., Mewburn, I., Thomson, P., Eds.; Routledge: London, UK, 2017; pp. 20-35.

23. Marshall, D.; Barbour, K.; Moore, C. Academic Persona: The Construction of Online Reputation in the Modern Academy. In The Digital Academic. Critical Perspectives on Digital Technologies in Higher Education; Lupton, D., Mewburn, I., Thomson, P., Eds.; Routledge: London, UK, 2017; pp. 47-62.

24. Luzón, M.-J. Constructing academic identities online: Identity performance in research group blogs written by multilingual scholars. J. Engl. Acad. Purp. 2018, 33, 24-39. [CrossRef]

25. Gurak, L.J. Ethos, Trust, and the Rhetoric of Digital Writing in Scientific and Technical Discourse from. In The Routledge Handbook of Digital Writing and Rhetoric Routledge; Taylor and Francis: Abingdon, UK, 2018; pp. 124-131. ISBN 9781315518497.

26. Bell, A.R. Has blogging changed science writing? J. Sci. Commun. 2012, 11, C02. [CrossRef]

27. Puschmann, C.; Mahrt, M. Scholarly blogging: A new Form of Publishing or Science Journalism 2.0? In Science and the Internet; Tokar, A., Beurskens, M., Keuneke, S., Mahrt, M., Peters, I., Puschmann, C., van Treek, T., Weller, K., Eds.; Düsseldorf University Press: Düsseldorf, Germany, 2012; pp. 171-181.

28. Mehlenbacher, A.R. Science Communication Online. Engaging Experts and Publics on the Internet; The Ohio State University Press: Columbus, OH, USA, 2019; ISBN 978-0-8142-1398-8.

29. Blanchard, A. Science Blogs in Research and Popularization of Science: Why, How and for Whom? In Common Knowledge: The Challenge of Transdisciplinarity; Cockell, M., Billotte, J., Darbellay, F., Waldvogel, F., Eds.; EPFL Press: Lausanne, Switzerland, 2011; pp. 219-232.

30. Mauranen, A. Hybridism, edutainment, and doubt: Science blogging finding its feet. Nord. J. Engl. Stud. 2013, 12. [CrossRef]

31. Russell, N. Communicating Science. Professional, Popular, Literary; Cambridge University Press: Cambridge, UK, 2010; ISBN 9780511803918.

32. Mewburn, I.; Thomson, P. Why do academics blog? An analysis of audiences, purposes and challenges. Stud. High. Educ. 2013, 38, 1105-1119. [CrossRef]

33. Gil-Salmon, L.; Soler-Monreal, C. Dialogicity in Written Specialised Genres; Benjamins: Amsterdam, The Netherlands, 2014.

34. Bolander, B. Disagreements and agreements in personal/diary blogs: A closer look at responsiveness. J. Pragmat. 2012, 44, 1607-1622. [CrossRef]

35. Luzón, M.J.; Pérez-Llantada, C. Science Communication on the Internet. Old Genres Meet New Genres; Benjamins: Amsterdam, The Netherlands, 2019. [CrossRef]

36. Zou, H.; Hyland, K. Reworking research: Interactions in academic articles and blogs. Discourse Stud. 2019, 21, 713-733. [CrossRef]

37. Yus, F. Interactions with Readers through Online Specialized Genres: Specificity or Adaptability? In Dialogicity in Written Specialised Genres; Luz Gil-Salmon, L., Soler-Monreal, C., Eds.; Benjamins: Amsterdam, The Netherlands, 2014; pp. 189-208, ISBN 9789027210401

38. Davis, J.L.; Jurgenson, N. Context collapse: Theorizing context collusions and collisions. Inf. Commun. Soc. 2014, 17, 476-485. [CrossRef]

39. Zou, H.; Hyland, K. "Think about how fascinating this is": Engagement in academic blogs across disciplines. J. Engl. Acad. Purp. 2019, 43, 100809. [CrossRef]

40. Freddi, M. Blurring the Lines between Genres and Audiences: Interaction in Science Blogs. Discourse Interact. 2020, 13, 9-35. [CrossRef]

41. Bondi, M. Try to prove me wrong: Dialogicity and audience involvement in economics blogs. Discourse Context Media 2018, 24, 33-42. [CrossRef]

42. Bondi, M. Blogs as interwoven polylogues. Lang. Dialog 2018, 8, 43-65. [CrossRef]

43. Sinclair, J.M. Trust the Text. Language, Corpus and Discourse; Routledge: London, UK, 2004; ISBN 9780415317689.

44. Hyland, K. Stance and engagement: A model of interaction in academic discourse. Discourse Stud. 2005, 7, 173-192. [CrossRef]

45. Bondi, M. Dialogicity in written language use. In From Pragmatics to Dialogue; Weigand, E., Kovecses, I., Eds.; Benjamins: Amsterdam, The Netherlands, 2018; pp. 138-170. [CrossRef]

46. Scott, M. Wordsmith Tools (8.0); Lexical Analysis Software: Stroud, UK, 2018.

47. Sinclair, J.M.; Mauranen, A. Linear Unit Grammar: Integrating Speech and Writing (Studies in Corpus Linguistics); John Benjamins: Amsterdam, The Netherlands, 2006; ISBN 9789027222985.

48. Hunston, S.; Thompson, G. Evaluation in Text: Authorial Stance and the Construction of Discourse; Oxford University Press: Oxford, UK, 2000; ISBN 0198299869.

49. Hunston, S. Corpus Approaches to Evaluation: Phraseology and Evaluative Language; Routledge: London, UK, 2011; Volume 13, ISBN 9780415836517 
50. Martin, J.R.; White, P.R. The Language of Evaluation; Palgrave Macmillan: London, UK, 2005; Volume 2, ISBN 13 978-1-4039-0409-6.

51. Tang, R.; John, S. The 'I' in identity: Exploring writer identity in student academic writing through the first person pronoun. Engl. Specif. Purp. 1999, 18, S23-S39. [CrossRef]

52. Vladimirou, D. I suggest that we need more research': Personal Reference in Linguistics Journal Articles. In Proceedings of the Lancaster University Postgraduate Conference in Linguistics E Language Teaching; Gabrielatos, C., Slessor, R., Unger, J.W., Eds.; Lancaster University: Lancaster, UK, 2007; pp. 139-157. Available online: https://www.lancaster.ac.uk/fass/events/ laelpgconference/papers/v01/Volume01.pdf (accessed on 20 January 2022). 